\title{
Analysis of Nitrogen and Amino Acid Contents in Cut and Potted Flowers of Eustoma grandiflorum
}

\author{
Saneyuki Kawabata* and Wanyi Chujo \\ Graduate School of Agricultural and Life Sciences, University of Tokyo, Yayoi, Bunkyo-ku, Tokyo 113-8657, Japan
}

The contents of total nitrogen and free amino acids of Eustoma grandiflorum were investigated during flower development and senescence in potted flowers, and were compared between potted and cut flowers, with or without sucrose supply. The total nitrogen content declined gradually as flower development and senescence proceeded in potted flowers. Detectable free amino acids by high performance liquid chromatography (HPLC) analysis in the petals were Asp, Glu, Asn, Gln, Ser, Phe, Gly, Thr, Ala, Tyr, and Val. The level of Gln was consistently high throughout flower development and senescence. Asn levels exhibited remarkable accumulation during flower senescence. The levels of other amino acids were much lower, but most showed a gradual increase until the initiation of wilting. Cut flowers without sucrose supply showed insufficient flower development and lower content of dry matter; however, total nitrogen content per corolla was not significantly different from potted flowers and cut flowers supplied with sucrose, resulting in a higher content of nitrogen per dry weight. These cut flowers without sucrose supply exhibited excessive accumulation of Asn and Gln at anthesis. Although nitrogen content per fresh weight or dry weight was slightly lower in the cut flowers with sucrose supply, their keeping quality was equivalent to potted flowers.

Key Words: asparagine, glutamine, lisianthus, sucrose, vase life.

\section{Introduction}

Nitrogenous substances such as amino acids and proteins constitute major organic compounds of plants. Nitrogen and amino acid metabolism has been suggested to play key roles in many aspects of flower development, including initiation of flowering, flower development and senescence. Imbalance between the relative availability of nitrogen to carbohydrate source has been recognized to associate with the initiation of flowering (Corbesier et al., 2002; Raper et al., 1988). A rise in the levels of several endogenous amino acids was suggested to be associated with floral transition in Lemna (Maeng and Khudairi, 1973; Tanaka and Takimoto, 1977). Nitrogen uptake may be stimulated during flower development as observed for Antirrhinum (Teresa et al., 1993) and pansy (Hamlin and Mills, 2001). The senescence of plant organs accompanies protein degradation and amino acid accumulation (Borochov and Woodson, 1989; Buchanan-Wollaston, 1997; Soudry et al., 2005).

Despite the importance of nitrogenous substances in the flowering process, there is limited information about the relationship between flower development and the availability of nitrogen in cut flowers. In contrast to nitrogenous substances, the positive effects of endogenous or exogenous sugar supply on the vase life of cut flowers have been studied extensively, and supplementary sugars are often used as preservatives of cut flowers by adding to the vase solution. Moreover, the addition of sucrose to Sandersonia flowers delayed glutamine (Gln) and asparagine (Asn) accumulation (Eason et al., 2000), which is normally observed during petal senescence. This suggested the sugar-dependent regulation of amino acid metabolism.

The purpose of this study was to provide basic information about nitrogen metabolism and changes in the content of nitrogenous compounds during the vase life of cut flowers of Eustoma grandiflorum. We investigated changes in the contents of total nitrogen and amino acids during flower development in potted flowers. In addition, the accumulation of these compounds was compared between potted plant and cut plants with or without sucrose supply. 


\section{Materials and Methods}

\section{Plant materials}

Seeds of Eustoma grandiflorum 'Azuma no Murasaki' were obtained from Sakata Seed (Yokohama, Japan). The seeds were sown on peat-based medium in midOctober and grown in a controlled environment at $20 \pm$ $2{ }^{\circ} \mathrm{C}$ under a $12 \mathrm{~h}$ light cycle of $10 \mathrm{klx}$ provided by cool white fluorescent tubes. After 1-2 months, the plants were transplanted in an individual polythene pots containing a 2:1 mixture of granulated soil (Engei Baido, Kureha, Tokyo, Japan) and peat-based soil mixture (Soil Mix, Sakata Seed). These plants were grown in a greenhouse until used for the experiment in spring. The plants were not pinched and only the first flower of each plant was used for analysis. The other flowers and buds were not removed.

\section{Changes during flower development and senescence}

Flowers were collected between 10:00 and 11:00 am at 9 developmental stages: stage 1, green buds, $2 \mathrm{~cm}$ long; stage 2, whitish green buds, $4 \mathrm{~cm}$ long; stage 3, initiation of petal unfolding and pigmentation; stage 4, petals half open, purple petals; stage 5, petals fully unfolded; stage 6, anthesis, pistil and stamens are open; stage 7 , initiation of wilting; stage 8 , initiation of color fading; stage 9, brown petals. After measuring the fresh weight and dry weight, the petals were frozen in liquid nitrogen within $30 \mathrm{~min}$ after harvest and stored at $-20^{\circ} \mathrm{C}$.

\section{Comparison between potted and cut flowers supplied} with or without exogenous sucrose

When the first flowers reached stage 2, cut plants were harvested, and then trimmed to $50 \mathrm{~cm}$. Each plant was held in a jar containing $100 \mathrm{ppm} 8$-hydroxyquinoline sulfate (8-HQS) (-Suc) or $100 \mathrm{ppm} 8$-HQS $+2 \%$ sucrose (+Suc) and placed at $20 \pm 2{ }^{\circ} \mathrm{C}$ under a $12 \mathrm{~h}$ light cycle of $1 \mathrm{klx}$ provided by cool white fluorescent tubes. Other potted plants were transferred to a growth room controlled at $20^{\circ} \mathrm{C}$ under natural light (Pot). These plants were collected when the flowers reached stage 6 . Another set of -Suc, +Suc, and Pot plants was used to record days from stage 2 to 6 and from stage 6 to 9 .

\section{Chemical analysis}

Carbon and nitrogen content in dried samples was determined using the CN-Corder (CN-90 system equipped with GC-14A, Shimadzu, Kyoto, Japan). Amino acids were extracted from $100 \mathrm{mg}$ dried tissue in a $1 \mathrm{ml}$ extraction solution consisting of methanol, water and chloroform $(12: 5: 3)$ at room temperature for three hours. Primary and secondary amino acids were labeled with fluorenylmethoxycarbonyl chloride (FMOC), according to Corbesier et al. (2001) with some modifications. For $50 \mu \mathrm{L}$ of the extract, $50 \mu \mathrm{L}$ of $20 \mu \mathrm{M}$ methionin (Met) dissolved in the extraction solution was mixed as an internal standard, because Met was not detectable in the petals of E. grandiflorum. Then, $50 \mu \mathrm{L}$ of $0.5 \mathrm{M}$ borate buffer ( $\mathrm{pH} 7.7$ ) was added. A $100 \mu \mathrm{L}$ aliquot of this solution was added with $100 \mu \mathrm{L}$ of $3 \mathrm{M}$ FMOC to initiate the derivatization. After 2-3 min, $200 \mu \mathrm{L}$ of $2 \mathrm{M} 1$-adamantamine dissolved in acetonitrile was added to quench the excess FMOC. After $60 \mathrm{~s}, 20 \mu \mathrm{L}$ of the reaction mix was sampled and diluted in a 20 fold volume of water, and then applied to a Shimadzu 10A high performance liquid chromatography (HPLC) system. Separation was performed on a C18 column (Pegasil ODS-II, Senshu, Tokyo, Japan) at $45^{\circ} \mathrm{C}$. The mobile phase was a mixture of solvent $(60: 40(\mathrm{v} / \mathrm{v})$ mixture of $10 \mathrm{mM}$ acetic acid-triethylamine $(\mathrm{pH} 6.3)$ and methanol) and solvent B (45:45:10(v/v) mixture of acetonitrile, methanol, and water) with an elution gradient in which the ratio of $\mathrm{B}$ to $\mathrm{A}$ was increased from 0 to $10 \%$ for $10 \mathrm{~min}$ and from 10 to $30 \%$ for $40 \mathrm{~min}$, and then raised to $100 \%$ for $15 \mathrm{~min}$. Flow rate was kept at $0.3 \mathrm{ml}$ per min. Fluorescence was detected by a fluorescence detector (RF 530, Shimadzu) with excitation at $265 \mathrm{~nm}$ and emission at $313 \mathrm{~nm}$.

\section{Results}

\section{Changes during flower development and senescence}

Flowers grown in the pots were collected at 9 developmental stages. The fresh weight of the corolla (Fig. 1) increased until the full opening stage (stage 6), and then decreased gradually until the end of senescence when petals turned brown (stage 9). Nitrogen content per fresh weight and per dry weight declined consistently during the whole developmental and senescence stages (Fig. 1).
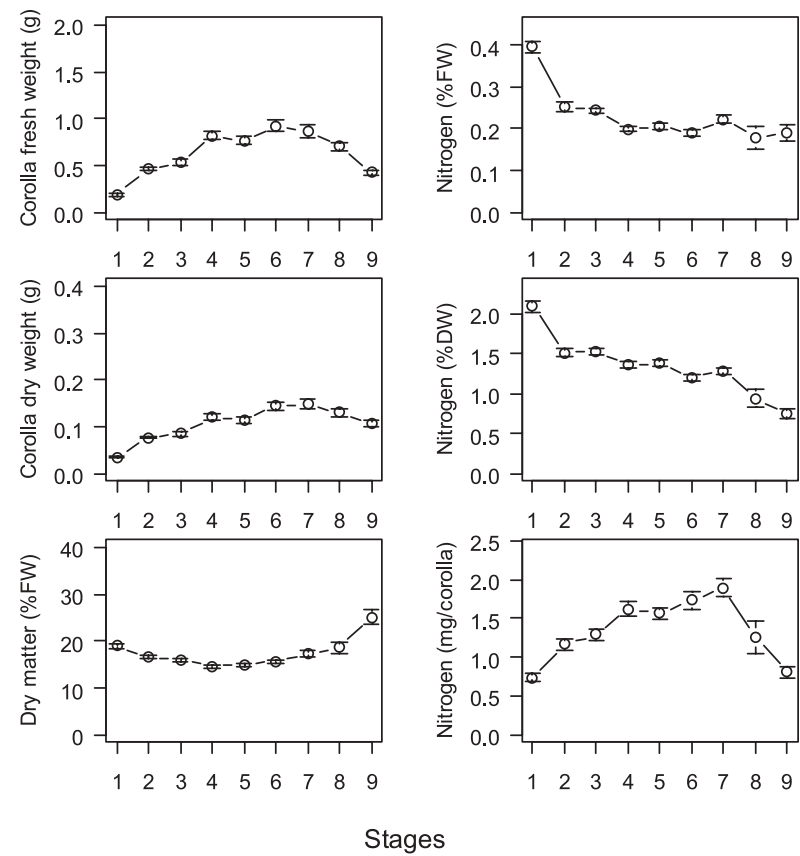

Fig. 1. Changes in corolla fresh weight, dry weight, dry matter content, total nitrogen content per fresh weight, per dry weight, or per corolla during flower development and senescence in potted flowers. Values are the means $\pm \operatorname{SE}(n=8)$. 

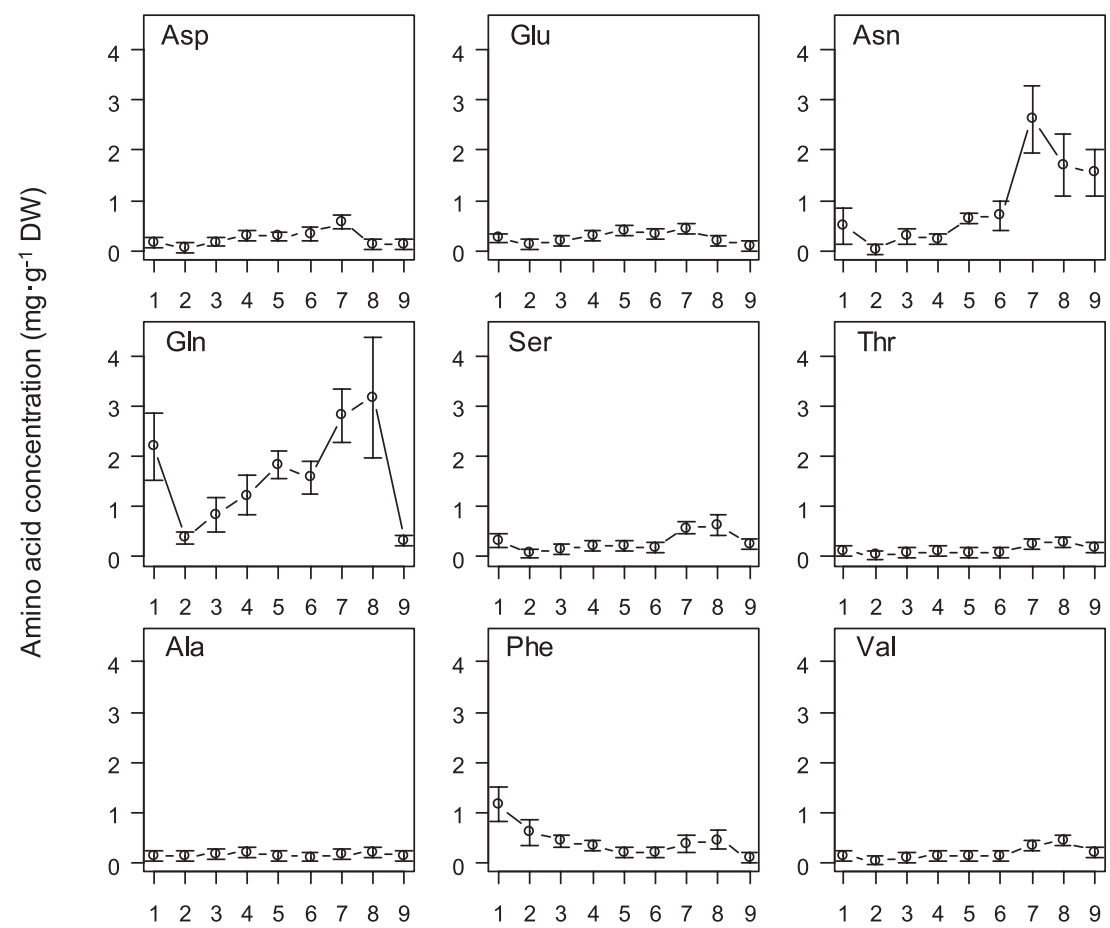

Stages

Fig. 2. Changes in contents of free amino acids in petals during flower development and senescence in potted flowers. Values are the means \pm SE $(n=8)$.

HPLC analysis of free amino acids detected aspartic acid (Asp), glutamic acid (Glu), asparagine (Asn), glutamine (Gln), serine (Ser), phenylalanine (Phe), glycine (Gly), threonine (Thr), alanine (Ala), tyrosine (Tyr), and valine (Val) in the petals of the Eustoma grandiflorum 'Azuma no Murasaki.' Changes during flower development for the top 9 amino acids are shown in Figure 2. Among these amino acids, Gln and Asn comprised a major portion of the total amino acid content. The level of Gln was consistently high throughout flower development and senescence, and showed an increase during senescence. The level of Asn was low during the young bud stages, and showed a rapid rise during senescence. The content of most amino acids, except for Phe, dropped at stage 2, and then increased gradually toward senescence.

\section{Comparison between potted and cut flowers supplied with or without exogenous sucrose}

-Suc flowers did not show sufficient development as compared with +Suc and Pot (Fig. 3). In -Suc, the fresh weight of the corolla was lower than + Suc and the dry weight of the corolla and dry matter content were lower than Pot and +Suc. The upper part of the -Suc stem also showed lower fresh weight, dry weight, and dry matter content than other treatments (Fig. 3).

Nitrogen accumulation per corolla in cut flowers (-Suc and +Suc) was almost the same as that of Pot (Fig. 4). This resulted in the highest nitrogen content per
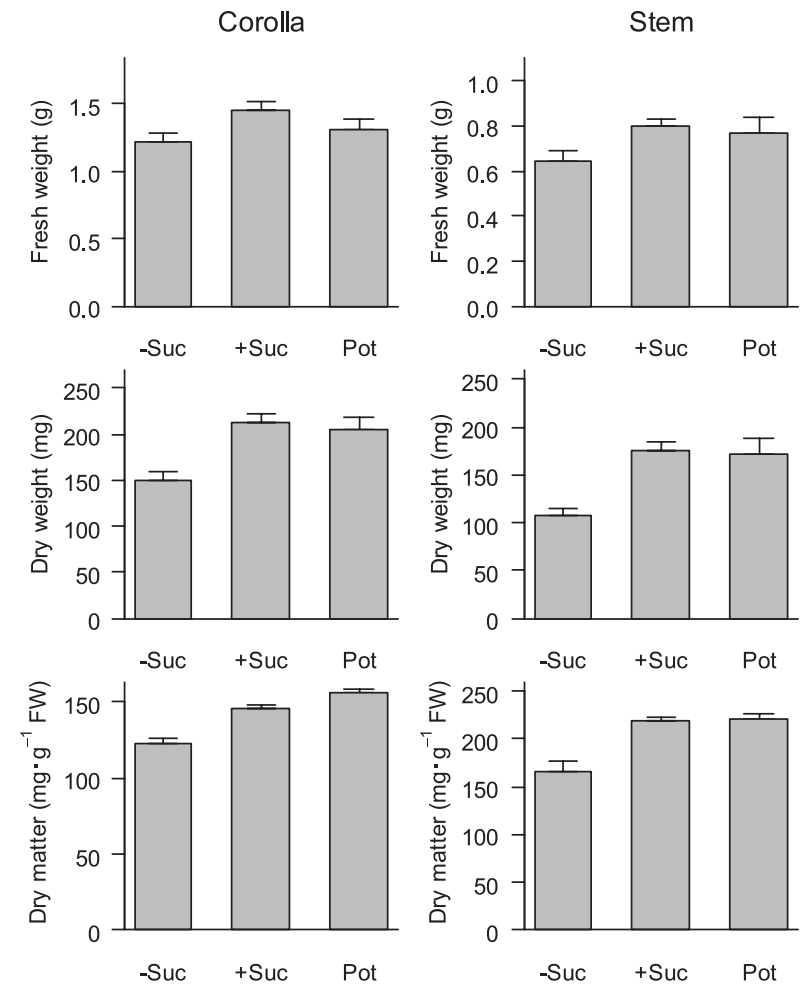

Fig. 3. Fresh weight, dry weight, and dry matter content of corollas and stems $(0-10 \mathrm{~cm}$ from the flowers) of cut flowers placed in $100 \mathrm{ppm} 8$-HQS (-Suc) or $100 \mathrm{ppm} 8$-HQS $+2 \%$ sucrose (+Suc), or in potted flowers (Pot) at anthesis (stage 6). Values are the means \pm SE $(n=10)$. 
Corolla
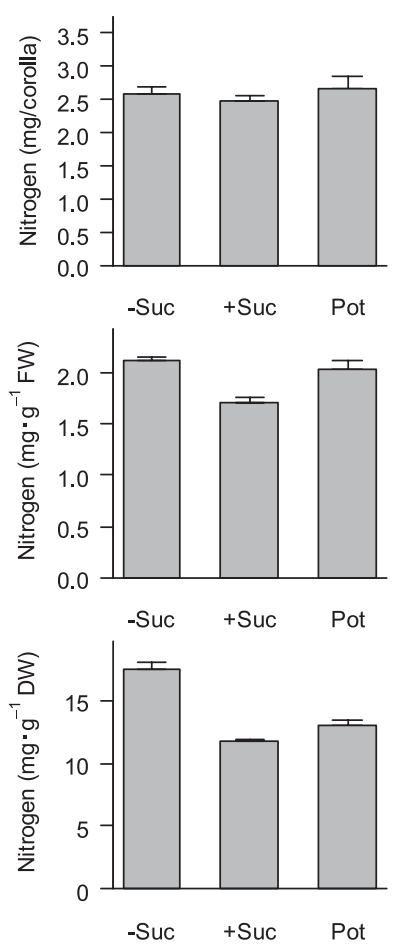

Stem
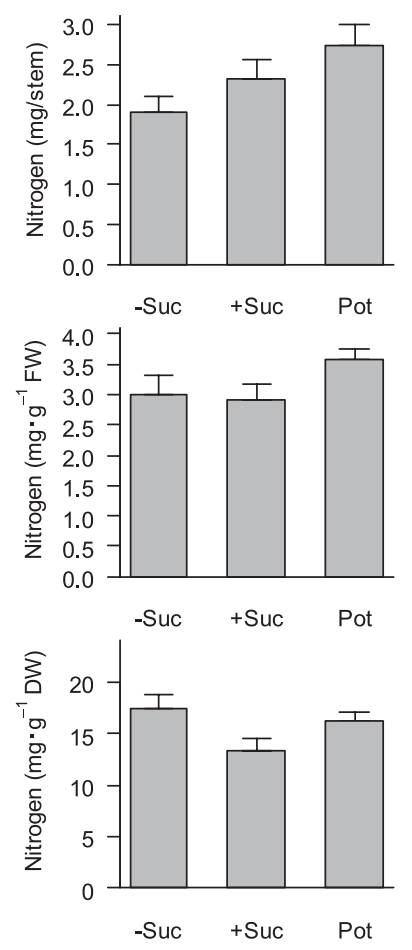

Fig. 4. Total nitrogen, contents of nitrogen per fresh weight or per dry weight in corollas and stems $(0-10 \mathrm{~cm}$ from flowers $)$ of cut flowers placed in $100 \mathrm{ppm} \mathrm{8-HQS} \mathrm{(-Suc)} \mathrm{or} 100 \mathrm{ppm} \mathrm{8-HQS+}$ $2 \%$ sucrose $(+\mathrm{Suc})$, or in potted flowers (Pot) at anthesis (stage $6)$. Values are the means $\pm \operatorname{SE}(n=10)$.

dry matter in -Suc in which dry matter accumulation was low. Nitrogen content per fresh weight and per dry weight was slightly lower in + Suc than in Pot. In the upper part of the stems, nitrogen content per dry weight was lowest in + Suc. Nitrogen content per stem was lower in both +Suc and -Suc than Pot (Fig. 4).

Days from stage 2 to stage 6 and days from stage 6 to stage 9 were not significantly different between treatments (Table 1). The apparent quality of flowers such as petal color and rigidity was clearly improved in +Suc than -Suc, but no difference was observed between + Suc and Pot.

Cut flowers of -Suc accumulated higher levels of free amino acids in the corollas (Fig. 5). The increase in amino acid contents in -Suc was found in almost all the amino acids detected, and the increase was most evident in Asn and Gln.

Table 1. Days from whitish green bud stage (stage 2) to anthesis (stage 6) and days from anthesis to the end of vase life (stage 9) in cut flowers placed in 8-HQS solution (-Suc) or 8-HQS $+2 \%$ sucrose (+Suc), or in potted flowers (Pot).

\begin{tabular}{rcc}
\hline \hline & \multicolumn{2}{c}{ Days } \\
\cline { 2 - 3 } & From stage 2 to 6 & From stage 6 to 9 \\
\hline -Suc & $5.4 \pm 0.60$ & $9.4 \pm 0.31$ \\
+ Suc & $5.5 \pm 0.52$ & $11.3 \pm 0.97$ \\
Pot & $5.0 \pm 0.56$ & $11.2 \pm 0.76$ \\
\hline
\end{tabular}

Values are the means $\pm \operatorname{SE}(\mathrm{n}=10)$
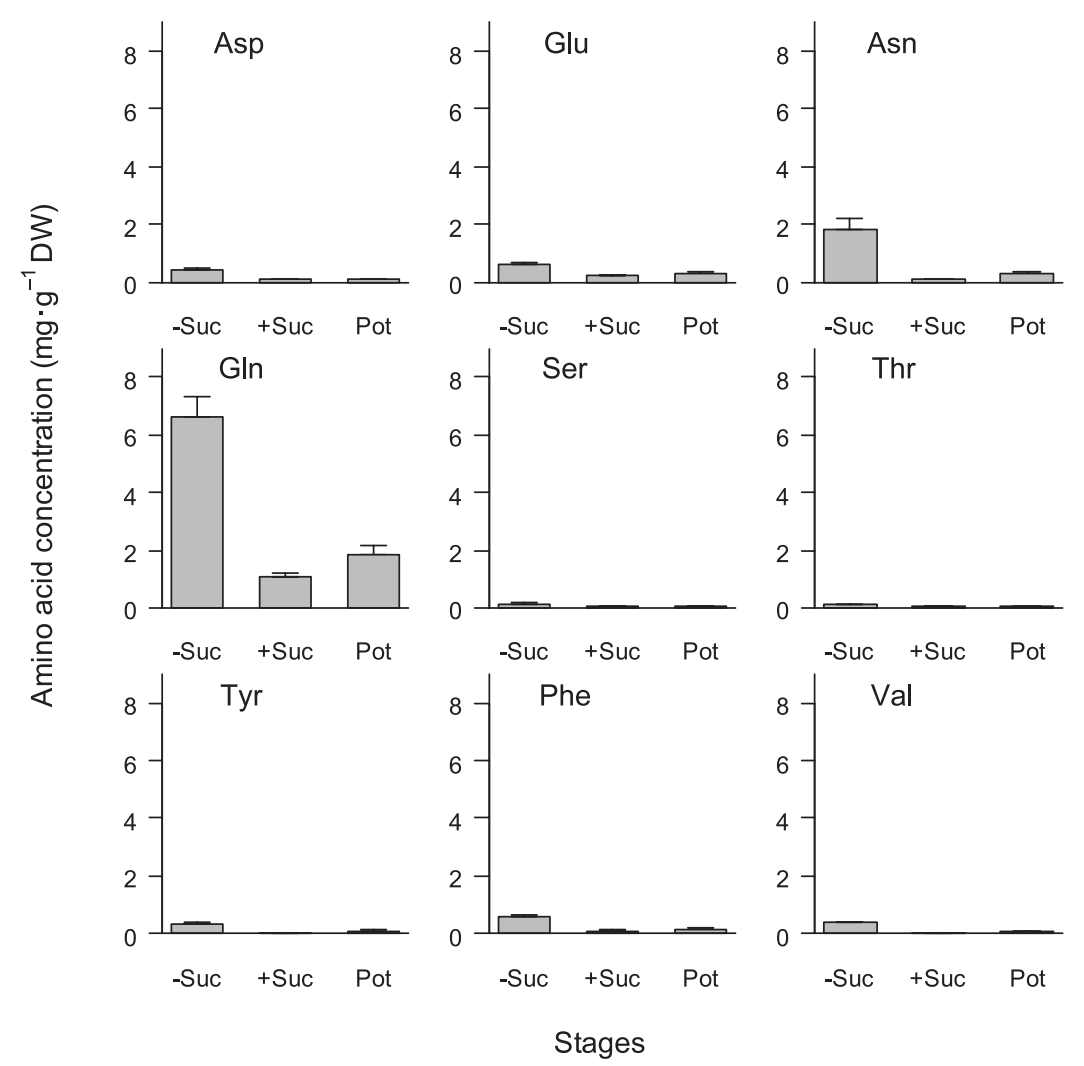

Fig. 5. Contents of free amino acids in petals of cut flowers placed in $100 \mathrm{ppm} 8$-HQS $(-\mathrm{Suc})$ or $100 \mathrm{ppm} 8-\mathrm{HQS}+2 \%$ sucrose (+Suc), or potted flowers (Pot) at anthesis (stage 6). Values are the means $\pm \operatorname{SE}(n=10)$. 


\section{Discussion}

Gln and Asn accumulation during senescence

Among the amino acids found in the petals, Gln and Asn exhibited remarkable accumulation during flowers senescence in E. grandiflorum flowers, as observed for Sandersonia aurantiaca (Eason et al., 2000) and carnation (van der Westhuizen and de Swardt, 1978).

The accumulation of Gln and Asn could be associated with the remobilization of assimilated nitrogen as proteins and other substances in the petals. Petal senescence accompanied a rapid loss of extractable protein (Eason et al., 1997; Woodson and Handa, 1987). A rise in protease activity during petal senescence was observed in several plant species (Rubinstein, 2000; Woodson, 1987; Woodson and Handa, 1987). Although total protein content was not measured in our study, the petals showed a drop in total nitrogen content per flower, which generally correlated well to the protein content.

Eason et al. (2000) reported the increased expression of asparagine synthetase (AS) during senescence and consistently high expression of glutamine synthetase (GS) in Sandersonia petals. Association of GS with senescence was often observed in other plants (Bernhard and Matile, 1994; Buchanan-Wollaston, 1997). Ammonia derived from the breakdown of proteins is incorporated into Gln catalyzed by GS for recycling. Although the primary route of ammonia assimilation is considered to be catalyzed by GS (Ireland and Lea, 1999; Lea and Miflin, 1980; Masclaux et al., 2001, MasclauxDaubresse et al., 2006), AS is potentially capable of assimilating ammonia into Asn (Lam et al., 1994). These products of ammonia assimilation are the major soluble amino acids that are used for nitrogen transport (Lea and Miflin, 1980; Urquhart and Joy, 1981, Sieciechowicz et al., 1988). Phloem sap collected from the cut end of the petiole contained Gln, Glu, Asn, Asp, and Ser, whereas the xylem sap contained mainly Gln in higher plants (Lam et al., 1994; Peoples and Gifford, 1990).

\section{Excessive accumulation of Gln and Asn under limited sugar supply}

Interestingly, the accumulation of Gln and Asn at anthesis (Stage 6) was much higher in cut flowers without sucrose supply (-Suc) than potted plants (Pot). This accumulation is partly attributable to the earlier initiation of senescence, as Eason et al. (2000) reported that the peak of Gln accumulation was delayed by sucrose supply. However, Gln accumulation was much higher in -Suc than in potted flowers at any stages of flower development including stage $7 / 8$ when potted flowers showed a peak of Gln accumulation; therefore, the accumulation should have been promoted under -Suc, at least for Gln.

The accumulated Gln and Asn could be either derived from transported nitrogenous substances from the source leaves or stems to the flowers or protein degradation products. Total nitrogen content per corolla in -Suc was equivalent to that of potted flowers. This implies that nitrogen supply from stems/leaves to flowers was sustained under limited sucrose supply. The protein degradation process and accompanying nitrogen metabolism in the petals under sucrose restriction would also have influenced the accumulation of Gln and Asn.

There are many studies concerning the expression of senescence-associated genes under sugar starvation (van Doorn, 2004). Fujiki et al. (2001) isolated several clones of sugar starvation-induced genes, which included AS. Thimann et al. (1977) hypothesized that sugar starvation is the direct cause of leaf senescence. Hoeberichts et al. (2007) found the down-regulation of senescenceassociated genes by sucrose in carnation petals. The low sugar level in -Suc petals might have stimulated the expression of GS and AS genes and production of Gln and Asn.

On the other hand, several reports suggested the repression of ammonia incorporation into amino acids under sugar starvation. Gln is not only the major amino acid used for nitrogen transport, but also a key metabolite that acts as an amino donor to other free amino acids, primarily catalyzed by Glu synthase (GOGAT). This pathway interacts with carbohydrate metabolism or the energy status of the organ (Finnemann and Schjoerring, 1999; Galvez et al., 1999; Hodges, 2002; Lancien et al., 2000). The enzymatic reaction of the GS/GOGAT pathway involves the transfer of the amino group from Gln to 2-oxoglutarate, which is derived from the TCA cycle (Joy, 1988). In addition, GS activity requires energy in the form of ATP.

Therefore, Gln and Asn accumulation was possibly caused by the sustained import of nitrogen from leaves or stems, as well as stimulated expression of GS or AS and reduced turnover of Gln and Asn, which couple the incorporation of nitrogen into the protein fraction under sugar starvation.

\section{Relationship between nitrogen supply and keeping quality of cut flowers}

In cut flowers, the only source of nitrogen for flowers is the stem or leaves where the available nitrogen amount is limited. The stems appear to be an important source of nitrogen for the corolla during flower development, because the upper part of the stems exhibited a reduction in nitrogen content, while the corolla of +Suc and -Suc contained an equivalent level of nitrogen as compared with Pot. Even though the nitrogen content per fresh weight and per dry weight in the petals of +Suc was slightly lower than in Pot, the apparent flower quality and vase life of + Suc were equivalent to Pot. Thus, nitrogen availability is unlikely to be a limiting factor of cut flower quality in E. grandiflorum.

The application of sugar to cut flowers is commonly used to extend their vase life, including E. grandiflorum, while the influence of nitrogen compound has attracted 
less interest. Nitrogen metabolism changes remarkably during flower development and senescence. In cut flowers of E. grandiflorum, the leaves or stems were found to serve as sufficient nitrogen sources for flower development, even though nitrogen content per dry weight or $\mathrm{N} / \mathrm{C}$ ratio was significantly lower in cut flowers supplied with sucrose than in potted flowers. Whereas carbohydrate shortage strongly influenced nitrogen metabolism, limited nitrogen supply in cut flowers did not seem to influence petal growth and the keeping quality of cut flowers. These results suggest that the benefit of applying nitrogenous compound exogenously would be limited to improve the keeping quality of E. grandiflorum cut flowers.

\section{Literature Cited}

Bernhard, W. R. and P. Matile. 1994. Differential expression of glutamine synthetase genes during the senescence of Arabidopsis thaliana rosette leaves. Plant Sci. 98: 7-14.

Borochov, A. and W. R. Woodson. 1989. Physiology and biochemistry of flower petal senescence. Hort. Rev. 11: 1543.

Buchanan-Wollaston, V. 1997. The molecular biology of leaf senescence. J. Exp. Bot. 48: 181-199.

Corbesier, L., A. Havelange, P. Lejeune, G. Bernier and C. Périlleux. 2001. N content of phloem and xylem exudates during the transition to flowering in Sinapis alba and Arabidopsis thaliana. Plant Cell Environ. 24: 367-375.

Corbesier, L., G. Bernier and C. Périlleux. 2002. C: N ratio increases in the phloem sap during floral transition of the long-day plants Sinapis alba and Arabidopsis thaliana. Plant Cell Physiol. 43: 684-688.

Eason, J. R., J. W. Johnston, L. de Vré, B. K. Sinclair and G. A. King. 2000. Amino acid metabolism in senescing Sandersonia aurantiaca flowers: cloning and characterization of asparagine synthetase and glutamine synthetase cDNAs. Aust. J. Plant Physiol. 27: 389-396

Eason, J. R., L. A. de Vré, S. D. Somerfield and J. A. Heyes. 1997. Physiological changes associated with Sandersonia aurantiaca flower senescence in response to sugar. Postharvest Biol. Technol. 12: 43-50.

Finnemann, J. and J. K. Schjoerring. 1999. Translocation of $\mathrm{NH}_{4}$ in oilseed rape plants in relation to glutamine synthetase isogene expression and activity. Physiol. Plant. 105: 469-477.

Fujiki, Y., Y. Yoshikawa, T. Sato, N. Inada, M. Ito, I. Nishida and A. Watanabe. 2001. Dark-inducible genes from Arabidopsis thaliana are associated with leaf senescence and repressed by sugars. Physiol. Plant. 111: 345-352.

Gálvez, S., M. Lancien and M. Hodges. 1999. Are isocitrate dehydrogenases and 2-oxoglutarate involved in the regulation of glutamate synthesis? Trends Plant Sci. 4: 484-490.

Hamlin, R. L. and H. A. Mills. 2001. Pansy floral development and nutrient absorption as influenced by temperature, nitrogen form, and stage of plant development. J. Plant Nutr. 24: 19751985.

Hodges, M. 2002. Enzyme redundancy and the importance of 2oxoglutarate in plant ammonium assimilation. J. Exp. Bot. 53: 905-916.

Hoeberichts, F. A., W. G. van Doorn, O. Vorst, R. D. Hall and M. F. van Wordragen. 2007. Sucrose prevents up-regulation of senescence-associated genes in carnation petals. J. Exp. Bot. 58: 2873-2885.
Ireland, R. J. and P. J. Lea. 1999. The enzymes of glutamine, glutamate, asparagine, and aspartate metabolism. p. 49-109. In: B. K. Singh (ed.). Plant amino acids: Biochemistry and biotechnology. Marcel Dekker, New York.

Joy, K. W. 1988. Ammonia, glutamine and asparagine: a carbonnitrogen interface. Can. J. Bot. 66: 2103-2109.

Lam, H. M., S. S. Peng and G. M. Coruzzi. 1994. Metabolic Regulation of the gene encoding glutamine-dependent asparagine synthetase in Arabidopsis thaliana. Plant Physiol. 106: $1347-1357$.

Lancien, M., P. Gadal and M. Hodges. 2000. Enzyme redundancy and the importance of 2-oxoglutarate in higher plant ammonium assimilation. Plant Physiol. 123: 817-824.

Lea, P. J. and B. J. Miflin. 1980. Transport and metabolism of asparagine and other nitrogen compounds within the plant. p. 569-607. In: B. J. Miflin (ed.). The Biochemistry of Plants, Vol. 5. Academic Press, New York.

Maeng, J. and A. K. Khudairi. 1973. Studies on the flowering mechanism in Lemna. I. Amino acid changes during flower induction. Physiol. Plant. 28: 264-270.

Masclaux, C., I. Quilleré, A. Gallais and B. Hirel. 2001. The challenge of remobilisation in plant nitrogen economy. A survey of physio-agronomic and molecular approaches. Ann. Appl. Biol. 138: 69-81.

Masclaux-Daubresse, C., M. Reisdorf-Cren, K. Pageau, M. Lelandais, O. Grandjean, J. Kronenberger, M. H. Valadier, M. Feraud, T. Jouglet and A. Suzuki. 2006. Glutamine synthetase-glutamate synthase pathway and glutamate dehydrogenase play distinct roles in the sink-source nitrogen cycle in tobacco. Plant Physiol. 140: 444-456.

Peoples, M. B. and R. M. Gifford. 1990. Long-distance transport of nitrogen and carbon from sources to sinks in higher plants. p. 434-447. In: D. T. Dennis and D. H. Turpin (eds.). Plant physiology, biochemistry and molecular biology. Longman, Harlow.

Raper Jr., C. D., J. F. Thomas, L. Tolley-Henry and J. W. Rideout. 1988. Assessment of an apparent relationship between availability of soluble carbohydrates and reduced nitrogen during floral initiation in tobacco. Bot. Gaz. 149: 289-294.

Rubinstein, B. 2000. Regulation of cell death in flower petals. Plant Mol. Biol. 44: 303-318.

Sieciechowicz, K. A., K. W. Joy and R. J. Ireland. 1988. The metabolism of asparagine in plants. Phytochemistry 27: 663671.

Soudry, E., S. Ulitzur and S. Gepstein. 2005. Accumulation and remobilization of amino acids during senescence of detached and attached leaves: in planta analysis of tryptophan levels by recombinant luminescent bacteria. J. Exp. Bot. 56: 695702.

Tanaka, O. and A. Takimoto. 1977. Flower-promoting effect of some amino acids and amides in Lemna paucicostata 6746. Plant Cell Physiol. 18: 27-34.

Teresa, M. H., H. A. Mills and P. A. Thomas. 1993. Developmental stage affects nutrient uptake by four snapdragon cultivars. HortScience 28: 1008-1010.

Thimann, K. V., R. M. Tetley, B. M. Krivak. 1977. Metabolism of oat leaves during senescence: V. Senescence in light. Plant Physiol. 59: 448-454.

Urquhart, A. A. and K. W. Joy. 1981. Use of phloem exudate technique in the study of amino acid transport in pea plants. Plant Physiol. 68: 750-754.

van der Westhuizen, A. J. and G. H. de Swardt. 1978. Changes in the individual free amino acid concentrations in the petals of carnation during the vase life of the flowers. $\mathrm{Z}$. Pflanzenphysiol. Bd. 86S: 125-134. 
van Doorn, W. G. 2004. Is petal senescence due to sugar starvation? Plant Physiol. 134: 35-42.

Woodson, W. R. and A. K. Handa. 1987. Changes in protein patterns and in vivo protein synthesis during presenescence and senescence of Hibiscus petals. J. Plant Physiol. 128: 67-75. Woodson, W. R. 1987. Changes in protein and mRNA populations during the senescence of carnation petals. Physiol. Plant. 71: 495-502. 